Please quote as: Bretschneider, U.; Ebel, P. A. \& Leimeister, J. M. (2020): Open Business Model Innovation via the Internet: How Digital Technologies Can Improve the Quality of Business Models. In: International Journal of Innovation and Technology Management (IJITM). 


\title{
Open Business Model Innovation via the Internet: How Wiki Technologies Can Improve the Quality of Business Models
}

\author{
Ulrich Bretschneider* \\ University of Hagen \\ Universitätsstraße 47, 58097 Hagen, Germany \\ ulrich.bretschneider@fernuni-hagen.de \\ Philipp Alexander Ebel ${ }^{\dagger}$ and Jan Marco Leimeister \\ University of St. Gallen \\ Institute of Information Management, Switzerland \\ ${ }^{\dagger}$ philipp.ebel@unisg.ch \\ \$janmarco.leimeister@unisg.ch
}

Received 13 June 2019

Revised 30 January 2020

Accepted 28 April 2020

Published

\begin{abstract}
Increasingly, firms follow the strategy of open business model innovation via the Internet. In this form of digital innovation management, firms make use of Internet platforms that allow them to integrate external customers and other stakeholders for (re-)innovation of their business models. However, the used IT tools on these Internet platforms suffer from not being able to merge the content of multiple users in an adequate way, thus the resulting business models suffer from low degrees of quality. Against this backdrop, in this research, we propose to equip these Internet platforms with a wiki technology. This would allow users to add to each other's content, to make changes or to correct mistakes. In our action design research (ADR), we could empirically validate that this leads to a higher quality in terms of business models' degree of elaboration. Since research that focusses on the design of Internet-based open BMI is still neglected, our research contributes to the literature base by being the first that answers ongoing open calls for research on this phenomenon of interest.
\end{abstract}

Keywords: Digital innovation management; open business model innovation; action design research; wiki.

\section{Introduction}

In 2003, Chesbrough has introduced the term "open innovation" as a concept for innovation where a company interacts strongly with its environment instead of using "closed" innovation processes located only within the research and development division of a firm. In open innovation, organizations pool knowledge, technologies 
and other assets from external stakeholders, in particular customers [Chesbrough (2003); Foss and Saebi (2016); Spieth and Schneider (2016)]. The basic idea behind this concept is that these stakeholders contribute their individual ideas, knowledge, experiences and strengths to pool complementary. More recently, literature and practice have begun to extend this concept to the field of business model innovation [Chesbrough (2007); Chiou (2011); Foss and Saebi (2017)]. Inspired by this, firms consider an open business model approach to take advantage of ideas, competences and resources external to them [Chesbrough (2006); Spieth and Schneider (2016); Hacklin et al. (2018)]. Companies use external ideas and knowledge from partner firms, suppliers or even customers in order to advance their business models or to invent new business models [Chesbrough (2006); Waldner and Poetz (2015); Nambisan et al. (2017)]. In literature, this is referred to as open business model innovation (open BMI) [Chesbrough and Schwartz (2007); Hacklin et al. (2018)].

New technological advancements, especially modern Internet platforms, allow practicing open BMI via the Internet, which constitutes a form of digital innovation management [Nambisan et al. (2017); Hacklin et al. (2018)]. On such Internet platforms firms bring together small groups of stakeholders in order to develop business models in a collaborative manner. These Internet platforms per se offer several opportunities for an improvement of open BMI, since they allow timeand location-independent connectivity of stakeholders [Tirabeni and Soderquist (2019)].

To provide stakeholders with a template for the collaborative development of business models, the input masks of these Internet platforms are typically developed according to logic of the so-called business model canvas (BMC) proposed by Osterwalder and Pigneur [2013]. This dialog box allows stakeholders to post their creative input separately for each building block of the BMC. However, this particular IT-tool on these Internet platforms constitutes a technology that only promotes a model of first-person storytelling and commenting [Wagner and Majchrzak (2007)]. We observed that the content for each building block of the BMC is organized chronologically, meaning the content of each contributor is simply listed in lines one below the other. This leads to the fact that after a while the content of each building block becomes not well elaborated. This, in turn, leads to the fact that the potential of the content is hardly identifiable or remains undetected.

In this research, we propose to implement a wiki technology for the described Internet platform instead of the traditional technology. In general, the wiki way is intended as a medium for collaborative, topical writing and editing [Wagner and Majchrzak (2007)]. A wiki technology would overcome the described shortcoming as each stakeholder could post his/her content to each building block whereupon others, without special authorization, could modify and/or expand the text to reflect their own thinking. Over time, with multiple edits, the resulting content may be of higher quality because it has been exposed to reactions of others in that way that each further content is not just organized in form of a list of different contents but rather merged with the previous content. This would lead to a much richer degree of elaboration. 
Against this background, we aim at developing a BMC dialog box that is based on the wiki technology. In a second step, we test and evaluate this IT tool. By doing so, we sought to find if open BMI with the help of this IT tool is more efficient by means of yielding more elaborated business models compared with virtual BMC frameworks that are supported by traditional technology.

\section{Open BMI via the Internet}

As described, special Internet platforms allow practicing open BMI via the Internet, which constitutes a form of digital innovation management [Nambisan et al. (2017); Hacklin et al. (2018)]. Firms run such Internet platforms to bring together small groups of stakeholders in order to develop business models in a collaborative manner. In this way, such Internet platforms per se offer several opportunities for making open BMI more efficient, since they allow time- and location-independent connectivity of stakeholders [Tirabeni and Soderquist (2019)].

\subsection{Internet platforms for open BMI in practice}

Practice originates several open BMI Internet platforms from different software providers, including LeanMonitor, Business Model Fiddle, BM DesignEr, Canvanizer or BMCanvas. All these platforms support open BMI, meaning that they provide an Internet-based environment allowing a decentralized and asynchronous development of business models of multiple individuals. All these Internet platforms have also in common that they use Osterwalder and Pigneur [2013] business model canvas (BMC) as a framework for the visualization of a business model. This visualization includes - according to the logic of the BMC — four "main areas", which are broken down into a set of nine building blocks that cover all relevant aspects of a business model. For each building block, there is a separate dialog box allowing users to contribute their content.

Unfortunately, this technology has some shortcomings: To organize the content, which once was posted by each contributor, the described platforms use a model of first-person storytelling and commenting. This means that the content for each building block of the BMC is simply listed in lines one below the other. In terms of the concept of semantic web, which is a collection of standards and approaches for bringing order and meaning to a certain kind of information on the Internet [Berners-Lee et al. (2001)], this logic is based on the semantic representation of communication behaviors of many-to-many, in which content is organized chronologically only. Typically, users are not able and authorized to delete, modify and/or expand content or bring certain parts of content in a new order to reflect their own thinking. This leads to the fact that after a while of producing knowledge the content of each building block is organized inefficiently in terms of its outcome [Wagner (2004)]. Because of the pure listing and the inability of merging new content with previous content, the content in each building block is only badly comprehensible and the potential of the content is hardly identifiable or remains undetected. 


\subsection{Literature on Internet platforms for open BMI}

Despite its undisputable relevance for practice, literature on Internet platforms for open BMI is relatively limited [Zott et al. (2011); Foss and Saebi (2016); Hossain (2017)].

Ebel et al. [2016] offer a theoretically develped framework that provides parctioneers a systematic approach for implementing Internet platforms for open BMI. This framework presents a set of general procedures and tools to systematically install and use such a platform in practice. In concrete, the framework explains and recommends which IT tool or IT functionallity has to be applied for certain activities Ebel et al. [2016]. However, the framework does not make any recommandations how to customize the design of such IT tools in order to make its use for open BMI more efficient.

Rohrbeck et al. [2013] go one step further and provide experience-based insights into the phenomenon of open BMI via the Internet. They conducted a case study of eight firms engaging in an open BMI in a face-to-face workshop setting [Rohrbeck et al. (2013)]. These firms collaborated to envision and create new business models in the energy industry. From the insights gained from these case studies, Rohrbeck et al. [2013] derived a generalized requirement for IT tools that enable open BMI via the Internet.

Another work by $\mathrm{Wu}$ et al. [2013] looked at IT tools for managing customerrelated knowledge (i.e. knowledge about customer, knowledge from customer and knowledge for customer) for BMI. These authors analyzed these IT tools concerning its usage on Internet platforms for open BMI [Wu et al. (2013)].

The works by Ebel et al. [2016], Rohrbeck et al. [2013] as well as Wu et al. [2013] are promising first steps; however, they stay on a mere theory level. Research that designs IT tools for the practical use of open BMI via the Internet is still neglected. This is surprising, since this form of digital innovation management is expected to facilitate the process of open BMI [Del Giudice and Straub (2011)] by reducing transaction costs and improving organizational routines when coordinating different development activities [Timmers (1998); Skinner (2008); Schneider and Spieth (2013); Tirabeni and Soderquist (2019)]. That is why literature is calling for more research on Internet-based open BMI for several years [Osterwalder and Pigneur (2013); Schneider and Spieth (2013); Veit et al. (2013); Hossain (2017)]. Our research will tap into this longstanding research gap by being the first that designs and evaluates a specific IT tool for such an Internet-based open BMI system.

\section{Research Methodology}

To frame our research, we generally chose a design science research approach because the aim of our research is to design an IT tool for a concrete problem and, in general, design science research follows a "learning through building" approach as the construction and evaluation of the artifacts is a means to study distinctive phenomena of a research domain [Kuechler and Vaishnavi (2011)]. Further, design science research involves the creation of new knowledge through design of novel or 
innovative artifacts and analysis of the use and/or performance of such artifacts along with reflection and abstraction, which ensures highly scientific claims [Kuechler and Vaishnavi (2011); Gregor and Hevner (2013)]. In 2011, Sein et al. [2011] introduce their action design research (ADR) method that proposes an adequate procedure for design science research specifically in IS settings. Thus, we chose $\mathrm{ADR}$ as the basic procedure for our research.

For processing our ADR research, we specifically followed the basic process steps proposed by the ADR approach. Hence, after defining the problem situation, deriving requirements and the initial design of the IT tool, our research followed a twoiteration logic. Each of the two iterations consisted of a piloting and evaluation step. The first iteration focusses on the piloting and evaluation of the alpha version of the IT tool in a limited setting, meaning we focussed on evaluating the usability of the IT tool in the first instance. After a reshaping of the alpha version on the basis of the insights of the first iteration, the second iteration focusses on testing and evaluating of the beta version of the IT tool in the real world setting, meaning at the Internet platform of the ERP software manufacturer SAP. So, the first iteration allowed for an intervention that was focussed on the IT tool itself, meaning that this iteration loop aimed at ensuring that the IT tool would been designed to later serve as an effective instrument for solving the underlying problem. The second iteration then allowed for a comprehensive piloting and evaluation of the IT tool in the use setting.

\section{Design of the IT Tool}

In our research, we use the Internet platform of the ERP software manufacturer SAP as a realworld case background, since SAP's Internet platform represents a typical example of the problem described earlier. The exact definition of the problem situation encountered in the specific organizational setting of SAP (see section entitled "Case background") allows us to systematically derive requirements for the IT tool (see section entitled "Requirements"). The definition of the problem situation together with the derivation of requirements then constitute premises that provide a platform for generating the initial design of the IT tool (see section entitled "Initial design of the IT tool"). This is what Sein et al. [2011] in their ADR methodology call a "practice-inspired research".

\subsection{Case background: Problem situation at SAP}

SAP is the world's leading manufacturer of ERP software. SAP is not especially known for its ERP software. Today, SAP also offers enterprise software, cloud services, among others, to manage business operations and customer relations. SAP offers its software products and services not only for large enterprises, but also for mid-sized companies and small businesses. SAP is a globally acting company with over 425,000 customers in over 180 countries.

Like other companies from the software industry, SAP has to face a hard competition. This situation puts increasing pressure on SAP to constantly adapt its business logic and processes in order to stay ahead of the market and their 
competition. As a consequence, the open BMI with selected customers who were scattered around different geographical locations around the globe has gained significant attention at SAP. This is seen by SAP as an effective instrument for the permanent illustration, innovation and evaluation of its business logic.

For practicing open BMI, SAP uses Internet platforms, meaning SAP brings together small groups of customers in these virtual environments in order to jointly develop business models with these customers in a collaborative manner. For doing so, SAP uses one of the above-described Internet platforms allowing a decentralized and asynchronous development of business models of multiple individuals. However, in everyday use this platform is reaching its limit as described earlier. As it is generally the case with these platforms, SAP customers are not able and authorized to delete, modify and/or expand content or bring certain parts of content in a new order to reflect their own thinking. This leads to the fact that after a while of producing knowledge, the content of each building block is organized inefficiently in terms of its outcome, meaning content is hardly identifiable or remains undetected.

According to a typical action research, this problem at SAP constitutes the starting point of our research, which was the basis to come up with the idea of implementing a wiki technology into SAP's Internet platform and replacing the traditional technology. We believe that a wiki technology would overcome the described shortcoming as each customer could post his/her content to each building block whereupon others, without special authorization, also could modify and/or expand the text to reflect their own thinking. We postulate that this will lead to a higher quality of the content, since the content would not just organize in form of a list but rather merged with the previous content, which, in turn, will lead to higher readability.

In general, practitioners as well as scholars have identified the wiki technology as an important technology for firms to work with customers, e.g. in the field of new product development [Fenn and Linden (2004); Hof (2004); Swisher (2004); Baker and Green (2005); Wagner and Majchrzak (2007)]. The assumption is that those organizations that can truly capture the technology's potential will experience dramatic improvements in the degree to which customers are engaged with the organization [Wagner and Majchrzak (2007)].

\subsection{Requirements for finding a solution strategy for the problem situation}

As described, existing Internet platforms supporting open BMI via the Internet only listed the content of each contributor in lines one below the other. This leads to the fact that after a while the content list becomes longer and longer and therefore suffers from complexity. Inevitably, the content list will also be poorly organized or contains doublets and mistakes at some points in time.

Hence, in order to avoid any redundancies and complexity and also poor organization of content, a new IT tool on the SAP platform should allow users to combine their knowledge with existing knowledge seamlessly. Further, to avoid 
errors and thereby to make use of the power of collective intelligence, the IT tool should allow users to correct errors of others.

A wiki's specific characteristic, that Wagner (2004) refers to as the "Power of N", would fulfill these requirements. In general, wikis create joint ownership of the work product [Wagner (2004)]. Each person can add to each other's content, if it is found to be incomplete [Wagner (2004)]. Further, each person can make changes. If a certain content is found to be redundant or poorly organized, any user can edit it as he/she sees fit [Wagner (2004)]. Further, users can help each other in correcting mistakes and work as a high performance team instead of a command-and-control structure that waits for an editor to approve additions or changes [Wagner (2004)].

\subsection{Initial design of the IT tool}

As described earlier, the IT tool of this research constitutes an input screen based on a wiki technology. This IT tool would represent only one component of the IT tools described above and that SAP use for practicing open BMI. Since such a software component does not exist yet on the market, we had to develop this IT tool ourselves and replace the current input screen by our IT tool. However, SAP's hitherto used IT tool is run under a proprietary license model, which made it impossible to simply embody our IT tool into this platform. Against this backdrop, we had to develop a reconstruction of the IT tool. This reconstruction constitutes an exact copy of SAP's IT tool with the sole exception that the input screen is not based on the common technology but on the wiki technology.

In the following, we describe the design of our IT tool, namely, the input screen with its inherent wiki technology. Following the example of conventional input screens, we designed the graphical interface of our input screen along the lines of the BMC proposed by Osterwalder and Pigneur [2013]. It consists of four "main areas", which are broken down into a set of nine building blocks (see Fig. 1). In other words, when designing the tool we followed exactly BMC's visualization concept in the form of a canvas, which represents all relevant aspects of the business model [Osterwalder and Pigneur (2010, 2013)].

Each building block represents one wiki page. So, our IT tool constitutes a collection of nine wiki webpages. For editing each page, users are offered a web-enabled form field to enter the content he/she wishes to publish. For doing so, user can use a simple markup scheme in the form of a simplified version of HTML. In addition to that, users were given the possibility to attach external data without any restrictions of its size and format.

As multi-user system, our wiki-based IT tool allows any user to modify any other user's content. This property creates numerous challenges in version management. We address these challenges by keeping prior versions of any web page in memory, and enabling rollback, comparison, difference identification. Furthermore, our IT tool provides a history of prior changes with author, date and related information. This revision history allows for the tracking of every change made by any user. Thus, all changes are traceable and on demand also can be reverted. 


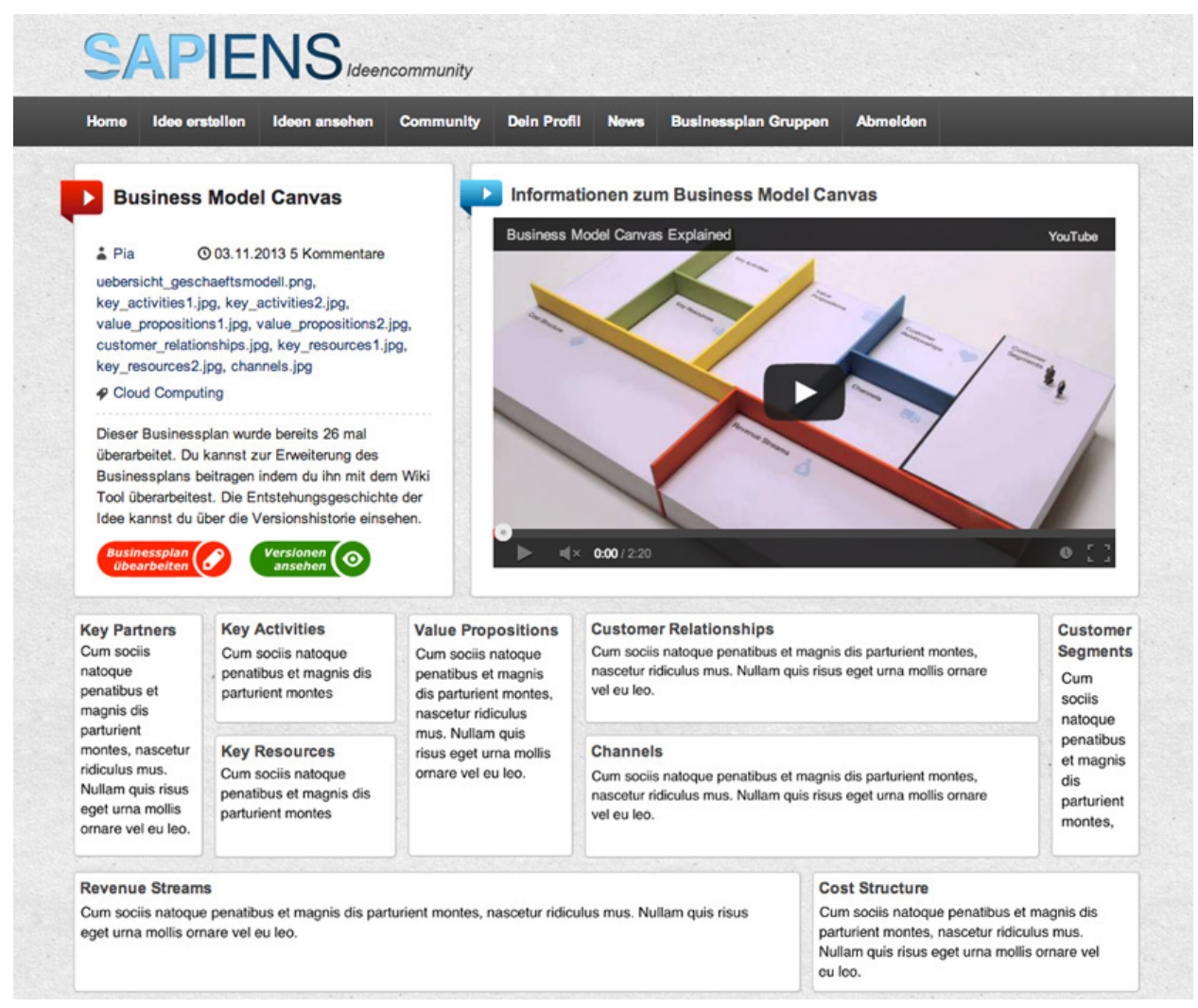

Fig. 1. Screenshot of the wiki-based dialog box.

\section{Piloting and Evaluation}

\subsection{First iteration: Piloting and evaluation in a limited setting}

The evaluation of this first iteration aims at ensuring that the alpha version of our IT tool will be designed to later serve as an effective instrument for solving the underlying research problem, namely, enabling open BMI via the Internet. We conducted this intervention in a limited context, which means that we assessed its usability.

In order to evaluate the usability, we use the Questionnaire for User Interaction Satisfaction (QUIS), which constitutes a standardized evaluation instrument in computer science for assessing the user interfaces of, for example, Internet platforms [Chin et al. (1988)]. It was developed to assess users' subjective satisfaction with specific aspects of a human-computer interface, such as the visible graphical interface features [Chin et al. (1988)]. In its current version, the QUIS contains a demographic questionnaire, a measure of overall system satisfaction along six scales, and hierarchically organized measures of nine specific interface factors. Each area measures the users' overall satisfaction with that facet of the interface on a 9 -point scale. The questionnaire is designed to be configured according to the needs 
of each interface analysis by including only the sections that are of interest to the user.

We focussed our evaluation on the following factors: overall user satisfaction, screen, terminology and system feedback, learning, system capabilities and multimedia. Other factors included in QUIS, such as teleconferencing and software installation as well as technical manuals, were not relevant for our case and thus were left out. In sum, 27 test-users participated in the evaluation of the artifact's first prototype. All the 27 test-users were SAP stakeholders that previously were engaged in developing BMI together with SAP via the old Internet platform. We chose an amount of 27 test-users in order to ensure representativeness according to the recommendations by Chin et al. [1988].

The testers were asked to develop a fictional business model in groups of up to five individuals. After the task was successfully completed, the testers were asked to answer the QUIS. For analyzing the results of the QUIS, we conducted an independent-samples $t$-test $(M>5)$. The results of this evaluation step are summarized in Appendix A.

As can be seen from Table A.1, a major weakness of the artifacts is that the used terminology does not relate well to the work situation $(t(22)=-0.284, p=0.779)$. The testers also criticized the system as too dull $(t(25)=0.814, p=0.423)$ and too rigid to cope with their needs $(t(25)=1.355, p=0.188)$. In the following section, we illustrate how these weaknesses were addressed when building the second instance of the artifact.

\subsection{Reshaping the IT tool}

In response to the evaluation insights, the IT tool was revised. In order to raise the user's perception of the system's capabilities, we implemented a feedback mechanism that would allow users to track the success of their actions. We also added supplementary information that explained the functions of platform and showed their significance for developing new business models to the users. To give the platform a more stimulating user interface, we decided to redesign the platform in terms of its outer appearance. Apart from the interface redesign, the platform was amended with multimedia content (e.g. video tutorials, visual representations of project goals). When looking at the inflexibility of the system, the test users mainly criticized their lack of freedom when attaching additional data to their business models, as well as the constraint to stick to a predefined format when adding information into their business models. As a consequence, we gave users the freedom to choose any kind of format when attaching additional data to their business models.

\subsection{Second iteration: Piloting and evaluation in the use setting}

\subsubsection{Testing}

This piloting involves testing the concept in the use setting. This iteration loop is thus focussed on checking if the IT-tool is able to solve SAP's underlying problem described in section titled "Case background". For the piloting phase, SAP initiated 
a further open BMI initiative with the help of our modified IT tool. The participants of this new initiative consist of the same 27 test-users that already attended the first iteration of testing. Participants were divided into six groups and each group was commissioned with the task to develop new business models for SAP's in-memory computing division. Participants were given six weeks to develop and elaborate their business models. Whenever they needed help in developing their business models, the teams could contact SAP in order to get professional advice. During the pilot phase, participants produced six business models.

\subsubsection{Evaluation}

To assess the value and utility of our IT tool, we had to evaluate the creative outcome of the business models that have been developed with the help of this IT tool. In other words, the IT tool can be interpreted as being useful when the emerging business models fulfill a certain level of quality, which means that the content of the business models is not just organized in form of a list but rather merged with the previous content, which, in turn, will lead to higher readability.

\subsubsection{Scale for assessing the quality of business models}

According to creativity research, business models can be interpreted as creative products. Creativity research has addressed the aspects of assessing creative products, such as ideas, paintings and so on [Amabile (1996a,b)]. Quality of creative products is a complex construct. Various metrics consisting of different dimensions for assessing the quality of creative products have been discussed in literature. To develop a reliable scale for our case, we searched for work done in creativity research. An extensive literature review was conducted, which identified several relevant papers that were useful for this research. First, all of these papers dealt with empirical evaluation of the quality of creative products. Secondly, all papers had in common that they used a certain scale for evaluating creative products. According to these criteria, we carefully analyzed the scales, particularly the used dimensions, in order to check which dimensions existed and which were appropriable for the development of the metric used for this evaluation.

The most appropriate dimension for this case was the dimension "elaboration". Elaboration is seen as the extent to which a creative product is complete, mature and well understandable [MacCrimmon and Wagner (1994); Dean et al. (2006)]. Applied to our case this means that if a business model that resulted from the pilot phase of the second iteration had a high degree of elaboration, one could conclude that users with the help of our IT tool were able to produce business models that do not suffer from poorly organized content or content that contains doublets and mistakes. In this way, we adopted the dimension elaboration for our scale. We operationalized elaboration by one item according to the above-mentioned definition ("The idea is complete, mature, and well understandable").

Apart from the dimension elaboration, the literature review revealed further dimensions, such as novelty, originality or feasibility. However, all these dimensions were inappropriate for the evaluation of our IT tool. 
5.3.2.2. The process of assessing business models

Because of the "fuzziness" of the creative products, a broad range of different evaluation methods for assessing the quality of creative products is discussed in literature and applied in practice [Plucker and Renzulli (1999)]. We made use of Amabile's Consensual Assessment Technique (CAT) [Amabile (1996a,b)] to evaluate all business models resulting from the piloting phase. By using the CAT method, an independent expert jury evaluated these business models. This jury consisted of three experts within the field of business model development at SAP. We choose these three experts, since each of them had at least five years of working experience within this field (average of 6.3 years).

For evaluation, each business model was pasted into separate evaluation forms, which also contained the above explained scale. Thus, six evaluation forms were handed out to each referee in a randomized order. All judges were assigned to rate the business models with the six different items on a rating scale ranging from one (lowest) to five (highest). Each member of the jury evaluated the business models independent of the others. According to [Amabile (1996a,b)], reliability of a scale that is used in the scope of Amabile's CAT is good if all judges of the jury evaluate the creative products concerning each dimension almost equal. That means that ratings on each dimension should be analyzed for inter-judge reliability [Amabile $(1996 a, b)]$. Consequently, we checked the inter-rater reliability for our case by calculating intra-class-correlation (ICC) coefficients. According to Amabile, ICC coefficients have to be higher than or equal to 0.7 in order to indicate a sufficient degree of inter-rater reliability [Amabile (1996a,b)]. In our case, the ICC coefficient for our scale "elaboration" was 0.866 , indicating a sufficient degree inter-rater reliability.

\subsubsection{Empirical results}

To express the degree of elaboration for each of the six evaluated business models, a quality index ranging from 3 to 15 was constructed. This index is calculated as follows: every business model's "elaboration" can have a maximum index of 5 per referrer. As there were three referrers, the maximum index for every business model is $5 * 3=15$. Accordingly, the minimum index is $1 * 3=3$. The evaluated business models reached quality scores between 5 and 12 (Table 1 ). The average value is 8500 and the standard deviation is 2588 . The Kolmogorov-Smirnov test confirmed the normality of the distribution $(p=0.200)$.

Table 1. Statistical results.

\begin{tabular}{lc}
\hline \multicolumn{1}{c}{ Statistical values } \\
$N$ & 6 \\
Average value & 8500 \\
Standard deviation & 2588 \\
Minimum & 5 \\
Maximum & 12 \\
Kolmogorov-Smirnov $Z$ & 0.243 \\
Asymptotic significance (bilateral) $(p)$ & 0.200 \\
\hline
\end{tabular}


U. Bretschneider, P. A. Ebel \& J. M. Leimeister

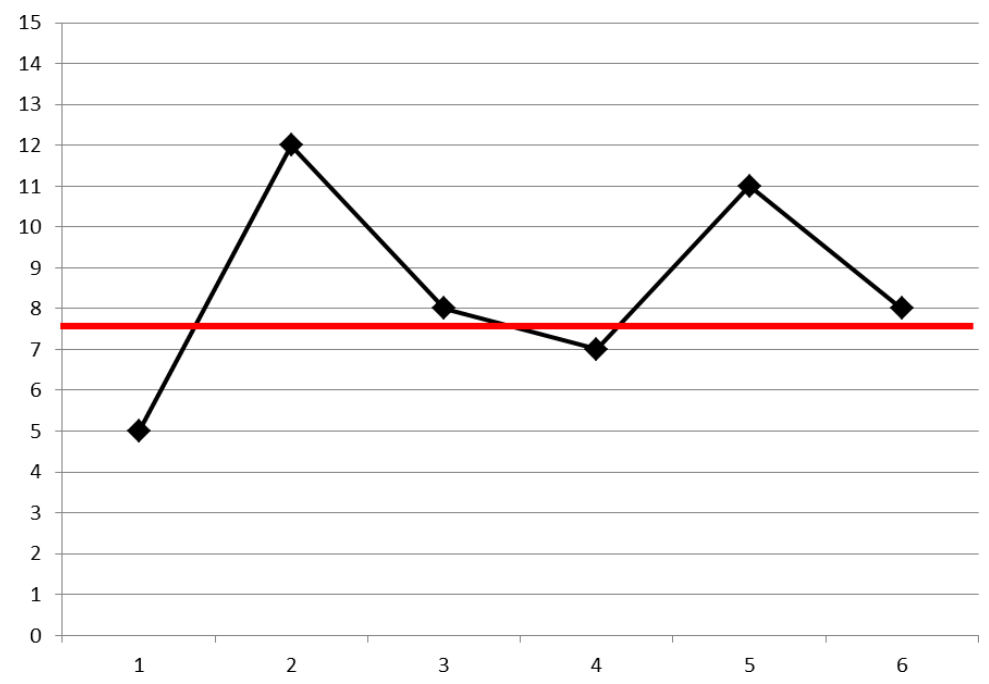

Fig. 2. Quality indices for the business models.

Figure 2 shows the quality indices for every evaluated business model. Compared to the maximum achievable 15 points per business model, the majority of the evaluated business model are above the medium level of 7500 (see red line in Fig. 2). These results thus clearly indicate a substantially good level of elaboration for the business models.

\section{Conclusion}

Our research aimed at equipping Internet platforms for open BMI with a wiki. The findings of the evaluation of our research reveal business models, which have been developed with the help of the wiki tool and have a sufficient degree of elaboration. Compared with the elaboration level of business models that emerged from SAP's former Internet platform, SAP confirms that the quality levels significantly rised. This indicates that our IT tool — the wiki technology — is useful to develop more elaborate business models.

As this was the first time a wiki technology was tested and evaluated for Internet platforms for open BMI, future research is needed to further test this concept in order to help shift this phenomenon of interest on a more general level and thereby help to maximize its validity. Nevertheless, this study provides an important initial indication for the proof of concept of the proposed IT tool. SAP, for its part, was surprised and very enthusiastic about the outcome of our ADR project.

\subsection{Limitations and future research}

Our findings must be seen in the light of the following limitations.

(1) One limitation involves the sample of our evaluation. The sample size was relatively small. Our results would certainly have been more meaningful with a higher sample size. For this reason, our results might impose some limitations 
concerning the generalizability. Future research should test and validate our wikibased IT tool by collecting more data sets, namely, more business models that emerge from this IT tool.

(2) Another aspect to be considered as a possible limitation and a future research aspect is that our findings may depend to a certain degree on the design of our IT tool. In general, study results from information systems research have proven that IT systems influence human behavior, meaning how users behave as a reaction of the use or perception of certain features of an IT system [Davis et al. (1989); Venkatesh (2000)]. However, we did not measure if certain IT functionalities, mechanisms, processes or other organizational structures of our IT tool impact the behavior of our test users. For example, we cannot ensure if a certain feature of the virtual environment stimulates or harms test users' collaboration behavior, creative urge or simply the use of the IT tool. Hence, future research should empirically validate the impact of our IT system on users' behavior, since this would certainly have an impact on the outcome of the open BMI via the Internet.

(3) A further limitation concerns the explanatory power of our results. Our results certainly would have been more meaningful with a comparison of the business models resulting from the IT tool before and after implementing the wiki technology. Since we did not measure the degree of elaboration of the business model that emerged from the IT tool without the wiki technology, we were not able to verify a significant improvement with the help of a $t$-test. Future research should consider this in order to provide a more explanatory power of the usefulness of wiki-based IT tools for BMI.

\subsection{Contribution to the body of knowledge and practice}

In this research, we could demonstrate that Internet platforms for open BMI, that are equipped with the wiki technology, help to produce business models that have a higher level of elaboration compared with business models that emerge from traditional Internet platforms for open BMI. As described, research that focusses on Internet-based open BMI is still neglected [Veit et al. (2013)]. This is surprising, since such a digital innovation management is expected to facilitate the process of open BMI [Del Giudice and Straub (2011)], which implies the high relevance for this research field. Hence, our research contributes to the literature base on Internetbased open BMI by being the first that examines this phenomenon of interest, thereby providing a possible initial step in this new field of research. By making this first step our research is the first answering ongoing open calls for research on Internet-based open BMI [Osterwalder and Pigneur (2013); Veit et al. (2013)].

Our research contributes also to the body of knowledge on Internet-based open BMI. As described, practice originates several open BMI platforms, including LeanMonitor, Business Model Fiddle, BM DesignEr, Canvanizer or BMCanvas. However, all these platforms have not implemented the wiki technology. Our research is the first that equipped Internet platforms for open BMI with the wiki technology and piloted and evaluated this technology for this class of Internet 
platforms. Thus, our research offers a fundamental new way how these Internet platforms work and therefore expands the body of knowledge.

Furthermore, our findings are of high relevance for practice, particularly for SAP. We could empirically validate a higher degree of elaboration for business models that emerge with the help of our IT tool. This is an important finding for SAP, who originally sought to increase the quality of business models that resulted from their open BMI initiatives. Hence, Internet platforms that are equipped with the wiki technology might also be a good opportunity for other companies that practice open BMI via the Internet. Until now, the wiki technology is generally identified as an important technology for firms to work with customers in various areas, e.g. in the field of new product development [Fenn and Linden (2004); Hof (2004); Swisher (2004); Baker and Green (2005); Wagner and Majchrzak (2007)]. The assumption is that those organizations that can truly capture this technology's potential will experience dramatic improvements in the degree to which customers are engaged with the organization [Wagner and Majchrzak (2007)]. Against the background of our research insights, this will be certainly also true for the field of open BMI.

\section{References}

Amabile, T. M. (1996a). Creativity in Context: Update to "The Social Psychology of Creativity". Westview Press, Boulder, CO, USA.

Amabile, T. M. (1996b). Creativity in Context: Update to the Psychology of Creativity. Westview Press, Oxford.

Baker, S. and Green, H. (2005). Blogs will change your business. BusinessWeek (May 2): $56-67$.

Berners-Lee, T., Hendler, J. and Lassila, O. (2001). The semantic web. Scientific American, $29-37$.

Chesbrough, H. (2006). Open Business Models: How to Thrive in the New Innovation Landscape. Harvard Business School Press, Boston, MA.

Chesbrough, H. W. (2003). The era of open innovation. MIT Sloan Management Review, 44, 3: 35-41.

Chesbrough, H. W. (2007). Why companies should have open business models. MIT Sloan Management Review, 48, 2: 22-28.

Chesbrough, H. and Schwartz, K. (2007). Innovating business models with co-development partnerships. Research Technology Management, 50, 1: 55-59.

Chin, J. P., Diehl, V. A. and Norman, K. L. (1988). Development of an instrument measuring user satisfaction of the human-computer interface. In Proceedings of the SIGCHI Conference on Human Factors in Computing Systems, ACM.

Chiou, C. H. (2011). Dynamic capabilities, collaborative network and business model: An empirical analysis of Taiwan HTC Corporation. African Journal of Business Management, 5, 2: 294-305.

Davis, F., Bagozzi, P. and Warshaw, P. (1989). User acceptance of computer technology - A comparison of two theoretical models. Management Science, 35, 8: 982-1003.

Dean, D. L., Hender, J. M. Rodgers, T. L. and Santanen, J. (2006). Identifying quality, novel, and creative ideas: Constructs and scales for idea evaluation. Journal of the Association for Information Systems, 7, 10: 646-699.

Del Giudice, M. and Straub, D. (2011). Editor's comments: IT and entrepreneurism: An onagain, off-again love affair or a marriage? MIS Quarterly, 35, 4: iii-viii. 
Ebel, P., Bretschneider, U. Leimeister, J. M. (2016). Leveraging virtual business model innovation: A framework for designing new business model development tools. Information Systems Journal, 26, 5: 519-550.

Fenn, J. and Linden, A. (2004). Hype cycle for emerging technologies. Gartner Strategic Analysis Report, G. Group, Stamford, CT.

Foss, N. J. and Saebi, T. (2016). Fifteen years of research on business model innovation: How far have we come, and where should we go? Journal of Management, 43, 1: 200-227.

Foss, N. J. and Saebi, T. (2017). Business models and business model innovation: Between wicked and paradigmatic problems. Long Range Planning, 51, 1: 9-21.

Gregor, S. and Hevner, A. R. (2013). Positioning and presenting design science research for maximum impact. MIS Quarterly, 37, 2: 337-355.

Hacklin, F., Björkdahl, J. and Wallin, M. W. (2018). Strategies for business model innovation: How firms reel in migrating value. Long Range Planning, 51, 1: 82-110.

Hof, R. D. (2004). Something wiki this way comes: They're web sites anyone can edit and they could transform corporate America. Business Week (June): 128.

Hossain, M. (2017). Business model innovation: Past research, current debates, and future directions. Journal of Strategy and Management, 10, 3: 342-359.

Kuechler, W. and Vaishnavi, V. (2011). Promoting relevance in IS research: An informing system for design science research. Information Science, 14, 1: 125-138.

MacCrimmon, K. R. and Wagner, C. (1994). Stimulating ideas through creativity software. Management Science, 40, 11: 1514-1532.

Nambisan, S., Lyytinen, K. Majchrzak, A. and Song, M. (2017). Digital innovation management: Rein-venting innovation management research in a digital world. MIS Quarterly, 41, 1: 223-238.

Osterwalder, A. and Pigneur, Y. (2010). Business Model Generation: A Handbook for Visionaries, Game Changers, and Challengers. Wiley and Sons, New Jersey.

Osterwalder, A. and Pigneur, Y. (2013). Designing business models and similar strategic objects: The contribution of IS. Journal of the Association for Information Systems, 14(Special Issue): 237-244.

Plucker, J. A. and Renzulli, J. S. (1999). Psychometric approaches to the study of human creativity. Handbook of Creativity. Cambridge University Press, New York, NY, USA, pp. 35-61.

Rohrbeck, R., Konnertz, L. and Knab, S. (2013). Collaborative business modeling for systematic and sustainable innovations. International Journal of Technology Management, 63, $1 / 2: 4-23$.

Schneider, S. and Spieth, P. (2013). Business model innovation: Towards an integrated future research agenda. International Journal of Innovation Management, 17, 1.

Sein, M., Henfridsson, O. Purao, S., Rossi, M. and Lindgren, R. (2011). Action design research. MIS Quarterly, 35, 1: 37-56.

Skinner, G. D. (2008). A study into fostering entrepreneurship in information communication technology (ICT). International Journal of Computers and Communications, 4, 2: $108-116$.

Spieth, P. and Schneider, S. (2016). Business model innovativeness: Designing a formative measure for business model innovation. Journal of Business Economics, 86: 671-696.

Swisher, K. (2004). Boomtown: "Wiki" may alter how employees work together. Wall Street Journal (July 29): B1.

Timmers, P. (1998). Business models for electronic markets. Electronic Markets, 8, 2: 3-8.

Tirabeni, L. and Soderquist, K. E. (2019). Connecting the dots: Framing employee-driven innovation in open innovation contexts. International Journal of Innovation and Technology Management, 16, 4.

Veit, D., Clemons, E. Benlian, A., Buxmann, P., Hess, T., Kundisch, D., Leimeister, J. M., Loos, P. and Spann, M. (2013). Business models - An information systems research 
agenda. Available at http://www.ise.tu-darmstadt.de/media/ise/publikationen_3/BMDiscussion-Paper-Veit-et-al.pdf [accessed on 26 November 2013].

Venkatesh, V. (2000). A theoretical extension of the technology acceptance model: Four longitudinal field studies. Management Science, 46: 186-204.

Wagner, C. (2004). Wiki: A technology for conversational knowledge management and group collaboration. Communications of the Association for Information Systems, 13: 265-289.

Wagner, C. and Majchrzak, A. (2007). Enabling customer-centricity using wikis and the wiki way. Journal of Management Information Systems, 23, 3: 17-43.

Waldner, F. and Poetz, M. K. (2015). Crowdsourcing business model innovation. Proceedings of the DRUID15, Rome.

Wu, J., Guo, B. and Shi, Y. (2013). Customer knowledge management and IT-enabled business model innovation: A conceptual framework and a case study from China. European Management Journal, 31, 4: 359-372.

Zott, C., Amit, R. and Massa, L. (2011). The business model: Recent developments and future research. Journal of Management, 37, 4: 1019-1042.

\section{Appendix A}

Table A.1. Results of the QUIS evaluation.

\begin{tabular}{|c|c|c|c|c|}
\hline Variable & Mean & S.D. & df & $t$ \\
\hline \multicolumn{5}{|l|}{ Overall user reactions } \\
\hline $\begin{array}{l}\text { Overall reactions to the system (ranging from } 1=\text { terrible to } \\
\quad 9=\text { wonderful) }\end{array}$ & 6.0769 & 1.99846 & 25 & $2.748^{*}$ \\
\hline $\begin{array}{l}\text { Overall reactions to the system (ranging from } 1=\text { frus- } \\
\text { trating to } 9=\text { satisfying) }\end{array}$ & 6.1923 & 1.91873 & 25 & $3.169^{* *}$ \\
\hline $\begin{array}{l}\text { Overall reactions to the system (ranging from } 1=\text { dull to } \\
9=\text { stimulating) }\end{array}$ & 5.2692 & 1.68660 & 25 & 0.814 \\
\hline $\begin{array}{l}\text { Overall reactions to the system (ranging from } 1=\text { difficult } \\
\quad \text { to } 9=\text { easy) }\end{array}$ & 7.5769 & 1.30148 & 25 & $10.096^{* * *}$ \\
\hline $\begin{array}{l}\text { Overall reactions to the system (ranging from } 1=\text { inade- } \\
\text { quate to } 9=\text { adequate) }\end{array}$ & 5.9231 & 1.97834 & 25 & $2.379^{*}$ \\
\hline $\begin{array}{l}\text { Overall reactions to the system (ranging from } 1=\text { rigid to } \\
\quad 9=\text { flexible) }\end{array}$ & 5.6154 & 2.31650 & 25 & 1.355 \\
\hline \multicolumn{5}{|l|}{ Screen } \\
\hline $\begin{array}{l}\text { Characters on the computer screen (ranging from } 1=\text { dull } \\
\quad \text { to } 9=\text { stimulating) }\end{array}$ & 7.9583 & 1.16018 & 23 & $12.492^{* * *}$ \\
\hline $\begin{array}{l}\text { Highlighting on the screen (ranging from } 1=\text { difficult to } 9= \\
\text { easy) }\end{array}$ & 6.7368 & 1.75885 & 18 & $4.304^{* * *}$ \\
\hline $\begin{array}{l}\text { Screen layouts were helpful (ranging from } 1=\text { inadequate to } \\
\quad 9=\text { adequate) }\end{array}$ & 6.2381 & 2.02249 & 20 & $2.805^{*}$ \\
\hline Sequence of screens (ranging from $1=$ rigid to $9=$ flexible) & 6.1111 & 1.81137 & 17 & $2.602^{*}$ \\
\hline \multicolumn{5}{|l|}{ Terminology and system information } \\
\hline $\begin{array}{l}\text { Use of terminology throughout system (ranging from } 1= \\
\text { inconsistent to } 9=\text { consistent) }\end{array}$ & 6.5000 & 1.41421 & 23 & $5.196^{* * *}$ \\
\hline $\begin{array}{l}\text { Terminology relates well to the work you are doing (ranging } \\
\quad \text { from } 1=\text { never to } 9=\text { always) }\end{array}$ & 4.8696 & 2.20133 & 22 & -0.284 \\
\hline $\begin{array}{l}\text { Messages which appear on screen (ranging from } 1= \\
\text { inconsistent to } 9=\text { consistent) }\end{array}$ & 6.6364 & 1.32900 & 21 & $5.775^{* * *}$ \\
\hline $\begin{array}{l}\text { Messages which appear on screen (ranging from } 1= \\
\text { confusing to } 9=\text { clear) }\end{array}$ & 6.7727 & 1.34277 & 21 & $6.192^{* * *}$ \\
\hline $\begin{array}{l}\text { Computer keeps you informed about what it is doing } \\
\text { (ranging from } 1=\text { never to } 9=\text { always) }\end{array}$ & 6.1500 & 1.46089 & 19 & $3.520^{* *}$ \\
\hline
\end{tabular}


Open Business Model Innovation via the Internet

Table A.1. (Continued)

\begin{tabular}{|c|c|c|c|c|}
\hline Variable & Mean & S.D. & df & $t$ \\
\hline $\begin{array}{l}\text { Error messages are (ranging from } 1=\text { unhelpful to } 9= \\
\text { helpful) }\end{array}$ & 6.2143 & 1.31140 & 13 & $3.465^{* *}$ \\
\hline \multicolumn{5}{|l|}{ Learning } \\
\hline $\begin{array}{l}\text { Learning to operate the system (ranging from } 1=\text { difficult } \\
\quad \text { to } 9=\text { easy) }\end{array}$ & 7.3750 & 1.83712 & 23 & $6.333^{* * *}$ \\
\hline $\begin{array}{l}\text { Exploration of features by trial and error (ranging from } 1= \\
\quad \text { discouraging to } 9=\text { encouraging) }\end{array}$ & 6.5600 & 2.14243 & 24 & $3.641^{* * *}$ \\
\hline $\begin{array}{l}\text { Remembering names and use commands (ranging from } 1= \\
\text { difficult to } 9=\text { easy) }\end{array}$ & 7.0556 & 1.58938 & 17 & $5.487^{* * *}$ \\
\hline $\begin{array}{l}\text { Tasks can be performed in a straight-forward manner } \\
\quad \text { (ranging from } 1=\text { never to } 9=\text { always) }\end{array}$ & 6.4545 & 1.99350 & 21 & $3.422^{* *}$ \\
\hline \multicolumn{5}{|l|}{ System capabilities } \\
\hline $\begin{array}{l}\text { System speed (ranging from } 1=\text { too slow to } 9=\text { fast } \\
\text { enough) }\end{array}$ & 7.6800 & 1.46401 & 24 & $9.153^{* * *}$ \\
\hline $\begin{array}{l}\text { The system is reliable (ranging from } 1=\text { never to } 9= \\
\text { always) }\end{array}$ & 7.3200 & 1.40594 & 24 & $8.251^{* * *}$ \\
\hline System tends to be (ranging from $1=$ noisy to $9=$ qui & 7.7778 & 1.71594 & 8 & $4.856^{* * *}$ \\
\hline $\begin{array}{l}\text { Correcting your mistakes (ranging from } 1=\text { difficult to } 9= \\
\text { easy) }\end{array}$ & 7.6471 & 1.80074 & 16 & $6.061^{* * *}$ \\
\hline $\begin{array}{l}\text { Ease of operation depends on your level of experience } \\
\quad \text { (ranging from } 1=\text { never to } 9=\text { always) }\end{array}$ & 7.7917 & 1.31807 & 23 & $10.376^{* * *}$ \\
\hline \multicolumn{5}{|l|}{ Multimedia } \\
\hline $\begin{array}{l}\text { Quality of still pictures/photographs } \\
\quad \text { (ranging from } 1=\text { bad to } 9=\text { good })\end{array}$ & 7.4375 & 1.67202 & 15 & $5.831^{* * *}$ \\
\hline Quality of movies (ranging from $1=$ bad to $9=$ good) & 7.4615 & 1.50640 & 12 & $5.892^{* * *}$ \\
\hline Sound output (ranging from $1=$ inaudible to $9=$ audible) & 7.3000 & 1.63639 & 9 & $4.445^{* *}$ \\
\hline Colors used are (ranging from $1=$ unnatural to $9=$ natural $)$ & 7.6667 & 1.29099 & 14 & $8.000 * * *$ \\
\hline
\end{tabular}

Note: ${ }^{* *}$ Significant at $0.001 ; * *$ significant at $0.01 ;{ }^{*}$ significant at 0.05 .

\section{Biography}

Ulrich Bretschneider is an Interim Professor of Information Management at the University of Hagen, Germany. He is also a research fellow at the Institute of Information Management (Competence Center Crowdsourcing) at the University of St. Gallen, Switzerland. His research interests focus on digitization of organizations. In particular, he is looking at Crowdsourcing for Innovation, IT-support for Business Model Innovation as well as diffusion of digital technologies and trends. His publications on these topics have appeared in the Journal of Management Information Systems, Information Systems Journal, Journal of Strategic Information Systems or the Proceedings of the International Conference on Information Systems.

Philipp Ebel is a postdoctoral research fellow and head of a research group at the Institute of Information Management (IWI HSG) at the University of St.Gallen, Switzerland. He is also a guest researcher at the Department of Information Systems at the University of Kassel, Germany. His research focuses on agile innovation, digital business models and hybrid intelligence. He teaches in various executive 
U. Bretschneider, P. A. Ebel \& J. M. Leimeister

education programs on these topics. Since 2011 he has been active as a consultant, trainer and member of the advisory board for various companies. His research work has been published in numerous renowned international journals and conferences.

Jan Marco Leimeister is Full Professor and Director at the Institute of Information Management, University of St.Gallen, Switzerland. He is furthermore Full Professor and Director of the Research Center for Information System Design (ITeG) at the University of Kassel, Germany. His research covers Digital Business, Digital Transformation, Service Engineering and Service Management, Crowdsourcing, Digital Work, Collaboration Engineering and IT Innovation Management. His publications on these topics have appeared among others in the Journal of Management Information Systems, Information Systems Journal, Journal of Strategic Information Systems or the Information Systems Research. 